\title{
Uma compreensão dos estudos de Joseph Campbell em mitologia comparada
}

\section{A comprehension on Joseph Campbell 's studies on comparative mythology}

Marcel Henrique Rodrigues ${ }^{1}$ Luis Antonio Groppo ${ }^{2}$
1 Graduando em Psicologia pelo Centro Universitário Salesiano de São Paulo (UNISAL). Pesquisador, categoria iniciação científica, em simbologia, psicanálise e religiões e membro da ABHR. Endereço eletrônico: marcel_symbols@ hotmail.com.

2 Professor do Centro Universitário Salesiano de São Paulo (UNISAL). Possui graduação em Ciências Sociais pela Universidade de São Paulo (1992), mestrado em Sociologia pela Universidade Estadual de Campinas (1996) e doutorado em Ciências Sociais pela Universidade Estadual de Campinas (2000). Atualmente é docente do Programa de Mestrado em Educação do Centro Universitário Salesiano de São Paulo e pesquisador inscrito no Conselho Nacional de Desenvolvimento Científico Tecnológico (CNPq). Endereço eletrônico: luis.groppo@am.unisal.br.

\section{Resumo}

A partir de um amplo estudo sobre mitos, símbolos e religiões, fomos descobrindo as obras de Joseph Campbell, um renomado mitólogo do século passado, considerado um dos maiores intelectuais que se esforçou para trazer a temática da mitologia e seus diversos símbolos para dentro do círculo científico e acadêmico da contemporaneidade. Este artigo visa debater e mostrar como os estudos de Campbell podem contribuir para o estudo das religiões a partir de uma óptica fenomenológica. Como método de trabalho, o estudo se baseia em algumas das principais obras de Campbell, dentre as quais a mais utilizada é A imagem mítica, pois, comparada com outros trabalhos do autor, essa obra abrange, de forma resumida, praticamente todos os conceitos formulados pelo estudioso durante seu percurso de investigação. Também será mostrado, no decorrer do artigo, de que maneira as teorias de outros autores, como o psicanalista Carl Jung e o antropólogo James Frazer, influenciaram diretamente as concepções de Joseph Campbell.

Palavras-chave: Joseph Campbell. Mitologia. Símbolos. Religiões

\begin{abstract}
From an extensive study of myths, symbols and religions, we discovered the works by Joseph Campbell, a renowned mythologist of the last century, considered one of the greatest intellectuals who struggled to bring the subject of mythology and its various symbols into the circle of contemporary scientific and academic fields. This article aims to discuss and demonstrate how the studies of Campbell can assist in the academic study of religions from a phenomenological perspective. This article was based on some of the major works of Campbell, however, the book used was The mythic image, given the fact that, compared with other works by the author, this book covers, in short, virtually all concepts formulated by Campbell during the course of his investigation. It will also be showed, throughout the article, a correlation of how the theories of other authors, as the psychoanalyst Carl Jung and anthropologist James Frazer, directly influenced the views of Joseph Campbell.
\end{abstract}

Key-words: Joseph Campbell. Mythology. Symbols. Religions 


\section{Introdução}

Este artigo é fruto de pesquisas realizadas por meio de bolsa de Iniciação Científica concedida pelo Conselho Nacional de Desenvolvimento Científico e Tecnológico (CNPq) entre os anos de 2010 e 2012. Os estudos sobre psicanálise, religiões e simbologia nos levaram às obras de Joseph Campbell, considerado um dos maiores mitólogos de todos os tempos e autor de uma extensa quantidade de livros publicados sobre temas como mitologia, religiões, psicologia das crenças e simbologia.

Os objetivos do trabalho são debater as principais ideias de Campbell sobre os mitos e a religiosidade e apresentar as implicações dessas ideias para o estudo da religiosidade na atualidade. Aos que se interessam pelo assunto da religiosidade, as obras desse autor são primordiais, pois exploram as grandes esferas das crenças em diversas eras históricas. Como se verá, este artigo se desenvolve com base no livro $A$ imagem mítica, obra que é, por si só, bastante extensa, abrangendo uma grande quantidade de imagens sagradas/religiosas de diversas civilizações e dos mais diversos tempos históricos, e que, portanto, nos fornece uma ideia geral acerca dos estudos desse intelectual.

Como já mencionado, Joseph Campbell é tido como um dos maiores mitólogos de todos os tempos. Seus trabalhos são considerados como obras-primas nos estudos comparativos de mitologia e de religiões e influenciaram várias áreas do conhecimento como Antropologia, Sociologia, Etnologia.

Campbell foi influenciado pelas ideias de Carl G. Jung, Sigmund Freud e James Frazer, que iniciaram os estudos sobre mitologia e sociologia da religião, e adotou conceitos advindos principalmente do círculo psicanalítico. Os estudos de Campbell proporcionaram ao mundo um novo entendimento sobre a religiosidade humana, trazendo à claridade, principalmente no mundo ocidental, os mitos e os ritos de diversos povos, como os da cultura chinesa, os da japonesa, os da australiana entre outros. A genialidade de Campbell consiste principalmente em sua capacidade de fazer comparações e criar analogias entre mitologias distintas e inseri-las no contexto ocidental, imbuído da religiosidade cristã, religiosidade essa que não deixa de ser estudada e analisada por esse pesquisador.

Campbell viveu em um período em que o ocidente estava redescobrindo outras culturas (como a oriental e a africana) e desvendando os mistérios dos povos précolombianos, que ainda permaneciam sob uma forte camada enigmática. Esse período marcou a cultura intelectual do ocidente, pois mostrou outras formas de manifestação religiosa, trouxe novos contextos históricos e antropológicos e evidenciou a maneira pela qual diferentes culturas encaravam a existência humana e de quais meios elas se utilizavam para explicar o universo. É dentro desse contexto que Joseph Campbell inicia seus estudos em mitologia comparada.

\section{Joseph Campbell e seus estudos em mitolo- gia}

A imagem mítica é um dos livros escritos por Campbell, e é nele que iremos basear o nosso trabalho, apontando as teorias, as investigações e as comparações que tornam a obra desse autor singular. Neste estudo apresentaremos outros teóricos que, como dito, influenciaram Campbell, sobretudo Jung (1983) e Frazer (1982).

No livro citado, Campbell relata a importância do conhecimento e dos estudos nas áreas de mitologia e de religiões de outros povos. Conhecemos por meio dos estudos e das críticas de Jung (1983), por exemplo, que a ocidentalidade conviveu por milênios com a religiosidade cristã, limitando-se aos muros da cristandade e deixando de lado outras culturas como a chinesa e a hindu, que, segundo a visão cristã, eram tidas como culturas embutidas de crenças pagãs. A redescoberta da cultura oriental, principalmente nos últimos dois séculos, proporcionou a Campbell um amplo campo para exploração a partir do qual ele conseguiu formular e teorizar sobre a importância dos estudos no campo da religiosidade. Segundo o autor, os símbolos religiosos de outras culturas são para os estudiosos um amplo material de conhecimento cultural, antropológico e histórico que fornecem ao homem não só um arcabouço intelectual, mas uma nova forma de encarar o mundo, a vida e a existência, contribuindo, assim, para a criação de um novo paradigma sobre as crenças religiosas.

Dissemos que Campbell acompanhou todo o percurso da "redescoberta" dos mitos orientais pelos estudiosos ocidentais. No entanto, apesar de sua ampla dedicação aos mitos do oriente, pelos quais sempre demonstrou uma verdadeira paixão, o autor também estudou amplamente os temas mitológicos do ocidente, sobretudo, os mitos cristãos, relacionando-os aos mitos orientais. 
Antes de analisarmos os principais temas mitológicos presentes em A imagem mítica, é necessário discutir o conceito de mito empregado pelo estudioso. Para Campbell (2009), o mito não é uma mentira ou algo irreal, concepção fortemente presente na mente dos ocidentais. Conforme o autor, um mito vem a ser uma chave para desvendar aquilo que os seres humanos têm em comum, que é a vocação para os mistérios, para o enigmático. É uma tendência inata humana voltar-se para os enigmas da vida, para o grande mistério da existência. Em resumo, os mitos tendem a fornecer significados para nossa existência, como podemos ver na citação abaixo sobre as funções dos mitos:

Os mitos têm basicamente quatro funções. A primeira é a função mística - e é disso que venho falando, dando conta da maravilha que é o universo, da maravilha que é você, e vivenciando o espanto diante do mistério. Os mitos abrem o mundo para a dimensão do mistério, para a consciência do mistério que subjaz a todas as formas. Se isso lhe escapar, você não terá mitologia. Se o mistério se manifestar através de todas as coisas, o universo se tornará, por assim dizer, uma pintura sagrada. Você está sempre se dirigindo ao mistério transcendente, através das circunstâncias de sua vida.

A segunda é a dimensão cosmológica, a dimensão da qual a ciência se ocupa - mostrando qual é a forma do universo, mas fazendo-o de uma tal maneira que o mistério, outra vez, se manifesta. Hoje, tendemos a pensar que os cientistas detêm todas as respostas. Mas os maiores entre eles dizem-nos: "Não, não temos todas as respostas. Podemos dizer-lhe como a coisa funciona, mas não o que é". Você risca um fósforo - o que é o fogo? Você pode falar de oxidação, mas isso não me dirá nada.

A terceira função é sociológica - suporte e validação de determinada ordem social. E aqui os mitos variam tremendamente, de lugar para lugar. Você tem toda uma mitologia da poligamia, toda uma mitologia da monogamia. Ambas são satisfatórias. Depende de onde você estiver. Foi essa função sociológica do mito que assumiu a direção do nosso mundo - e está desatualizada.

Existe uma quarta função do mito, aquela, segundo penso, com que todas as pessoas deviam tentar se relacionar - a função pedagógica, como viver uma vida humana sob qualquer circunstância. Os mitos podem ensinar-lhes isso. (CAMPBELL, 2010, p. 23).

A partir dessa explicação, é possível observar a grande importância que Campbell (2010) dá ao mito, ao tratá-lo como algo que é vivo e que pode influenciar a vida dos sujeitos.
Em A imagem mítica, Campbell faz uma comparação entre suas análises e as teorias sobre o inconsciente coletivo formuladas por Jung (2008). Esse psiquiatra suiço, amigo e dissidente de Sigmund Freud, foi um profundo estudioso da psique humana e também um apaixonado por religiões, mitologia e simbologia. Seus estudos estavam embasados em concepções psicológicas que o levaram, perante as similaridades entre mitos, crenças e símbolos de diversos povos, separados geograficamente, a concluir que existe, além de um inconsciente individual, um inconsciente coletivo, ou seja, um inconsciente compartilhado por todos os homens, independentemente da época ou local geográfico em que estão inseridos. É assim que Jung expressa sua tese:

O inconsciente coletivo é uma parte da psique que pode distinguir-se de um inconsciente pessoal pelo fato de que não deve sua existência à experiência pessoal. Enquanto o inconsciente pessoal é constituído essencialmente de conteúdos que já foram conscientes e no entanto desapareceram da consciência por terem sido esquecidos ou reprimidos, os conteúdos do inconsciente coletivo nunca estiveram na consciência e portanto não foram adquiridos individualmente, mas devem sua existência apenas à hereditariedade. (JUNG, 2008, p. 53).

É a partir desse conceito que Campbell se aventura em uma profunda pesquisa na busca de analogias entre mitos orientais e mitos ocidentais. A imagem mítica é a principal obra que congrega, de forma concreta e clara, os resultados dessa sua pesquisa.

Campbell também faz uma série de referências ao pai da Psicanálise, Sigmund Freud, a quem considera como uma personalidade ímpar e um profundo estudioso da mente humana, aquele que libertou a civilização de antigos tabus e ofereceu uma chave para a compreensão da psique humana. No entanto, o mitólogo faz abertas críticas a Freud, que via os mitos e as crenças como uma "válvula de escape" para a energia libidinal reprimida. Por exemplo, a crença em Deus, segundo Freud (2006), é um retorno ao mundo infantil no qual o sujeito, incapaz de se ver longe da proteção de seu pai, cria um novo pai onipotente e onipresente que é chamado de Deus. Campbell não concorda com essa visão freudiana sobre os mitos e, em seu lugar, apresenta uma maneira inovadora de tratar as mitologias: como uma fonte filosófica e inspiradora para encarar e interpretar a vida. 


\section{A análise dos escritos de Joseph Campbell com base na obra $A$ imagem mítica}

O objetivo deste artigo não é ser uma resenha nem um resumo do livro $A$ imagem mítica, mas sim, produzir um referencial para que o leitor compreenda a maneira como Joseph Campbell estuda os mitos e os símbolos em suas obras científicas e que lhe confere o título de maior mitólogo da atualidade.

O título do livro trata de imagens míticas, ou seja, imagens sagradas para determinada cultura. Como afirma o autor: "Imagens convidam os olhos a não se apressar, mas sim a descansar por um instante e a se abstrair com elas no enlevo de sua revelação" (CAMPBELL, 1994, p. 9). Essa frase merece atenção, pois, além de fazer um convite ao leitor para meditar acerca dos símbolos, traz um conceito científico sobre eles. Com efeito, conforme mostra Santos (1959), a linguagem dos símbolos é "silenciosa" e tem como objetivo "revelar-velando", ou seja, cada símbolo tende a manifestar uma mensagem, um conteúdo, de forma velada, e o sujeito só chegará ao seu significado por meio da meditação.

Podemos dizer que Campbell (1994), ao analisar imagens sagradas das mais diversas culturas e promover a comparação entre elas, não está praticando um ato de denegrir as imagens simbólicas, mas está mostrando ao mundo o quanto o ser humano é espiritual e que, desde que existe vida humana na terra, já havia resquícios de culto ao sagrado, ou melhor dizendo, de culto ao mistério da existência.

Tal experiência é constatada em exemplos clássicos da história das culturas que, de certa forma, se inter-relacionam, devido as suas similaridades. É a partir desse critério que encontramos, nas culturas, conceitos milenares: bem e mal, feminino e masculino, sagrado e profano. Esses conceitos, como aponta o autor, são conceitos clássicos que permitiram a produção de símbolos e a sua adaptação de culturas para culturas.

Campbell (1994) cita o exemplo de duas culturas, a mesopotâmica e a pré-colombiana que, pelo que se sabe, nunca entraram em contato. Essas duas civilizações distintas possuem símbolos, ritos e mitos muito parecidos quando comparados e analisados. Suas crenças resultaram em construções de templos para os cultos religiosos e sacrificais. As conhecidas pirâmides dos maias e dos astecas e os zigurates dos mesopotâmios, por incrível que pareça, são esteticamente muito parecidas e possuíam as mesmas funções para culto e sacrifício aos deuses, além de estarem alinhadas de acordo com a posição dos astros. O autor concluiu, assim como outros antropólogos e estudiosos, que essas semelhanças não poderiam ter sido fruto de contato entre esses povos na antiguidade ${ }^{3}$.

Mallon (2009) partilha da mesma concepção de Campbell (1994) de que a humanidade sempre teve necessidade de adorar os mistérios da natureza e, por conta disso, produziu e construiu monumentos simbólicos que revelam uma incrível similaridade de cultura para cultura.

Após entendermos o método usado por Campbell para construir seu raciocínio, apontaremos os principais eixos discutidos em $A$ imagem mítica, pois, este artigo, ao final, fornecerá ao leitor a uma reflexão de que as crenças, os mitos e as religiões não são fenômenos isolados, mas partem de crenças que muitas vezes são partilhadas por toda a humanidade.

Uma das principais concordâncias míticas analisadas por Campbell (1994) é extraída do Cristianismo, que, por séculos, pregou a singularidade da história de Jesus Cristo, bem como de toda a Bíblia ${ }^{4}$.

Um mito muito difundido por todo o mundo, sobretudo no oriente, é o mitologema ${ }^{5}$ do nascimento e morte de um Deus. Campbell (1994) nos relata o mais conhecido deste mitologema na atualidade: o nascimento virginal de Jesus (o filho de Deus) que morre e ressuscita. De modo análogo, há o mito de Osíris, Ísis e Hórus, denominada de tríade egípcia, na qual Hórus, filho de Ísis, havia nascido virginalmente, e o marido de Ísis, o poderoso Osíris, ressuscita dos mortos após o nascimento de Hórus. A mesma temática é analisada por Jung (1983),

3 Apesar de estudar as similaridades mitológicas e simbólicas de diferentes culturas, Campbell é cauteloso quanto a propor a existência de um inconsciente coletivo, como postulado por Jung (2008), mas não nega que isso seja uma possibilidade plausível e evidente.

4 Tal estudo já havia sido desenvolvido por Frazer (1982) em seu mundialmente conhecido livro O ramo de ouro. O próprio Jung (1983), em seus estudos sobre a religião oriental e a ocidental, também mostrou a similaridade entre antigos e diversos cultos pagãos (até então demonizados pela cristandade) com os próprios rituais do Cristianismo, como o seu estudo sobre a Eucaristia cristã.

5 Segundo Alvarenga et al (2010, p. 15), mitologema é o conjunto de histórias míticas que traduzem a mesma temática (por exemplo, mitologemas do rapto, mitologemas do nascimento virgem, mitologemas da iniciação feminina etc). 
que conclui que tal similaridade não se limita a esses dois mitos. Existe analogia com o mito de Buda que, nascido de uma virgem, viveu pregando o desapego material e com o mito do deus grego Dionísio, que, após a morte, retornou em um ato de ressurreição.

O que é apresentado por esses estudiosos são as semelhanças entre temas mitológicos. O interesse dos autores não está voltado para menosprezar os temas míticos ou para desvalorizar alguma religião. Eles querem demonstrar a profundidade dos mitos e mostrar sua caracterização como necessidades existenciais da humanidade. Além disso, eles também pretendem comprovar que todos os povos necessitam de heróis e de deuses, que tudo podem, que salvam e que fornecem esperança diante do grande enigma da vida.

A temática dos heróis míticos é amplamente exposta por Campbell em seu livro O herói de mil faces, que traz os mitologemas de heróis de diversos cantos do mundo, nas mais diferentes eras. Além de mostrar os grandes heróis da humanidade como o Shiva hindu, o Prometeu grego e o Hórus egípcio, o mitólogo aborda estudos sobre temas ritualístico-simbólicos que foram e ainda são utilizados por diversas tradições a fim de transformarem os seres humanos em heróis de sua própria história ou mesmo integrá-los com o divino.

Entre os temas analisados por Campbell (2007) estão, sobretudo, aqueles relacionados à figura bíblica de Jonas, que, segundo a tradição, foi engolido por uma baleia e, após três dias, saiu do ventre do animal como um novo homem. Esse mito também está presente em culturas africanas, asiáticas e europeias e, acima de tudo, constitui um grande ensinamento para os homens sobre a possibilidade de renovar suas vidas no decorrer da sua jornada. Em nossa cultura ocidental, podemos observar a existência desse tema mítico em rituais cristãos como, sobretudo, no rito do batismo, em que, simbolicamente, morre o velho homem corrompido pelo pecado de Adão, e renasce um novo homem para a vida e para o amor em Cristo.

Outro aspecto muito interessante trazido pelo autor consiste no estudo da rica e enigmática simbologia de igrejas europeias em estilo gótico. Como exemplo, cita-se a Catedral de Notre Dame, em Paris, cujo exterior é ornamentado com estranhas criaturas conhecidas como gárgulas, que se apresentam com corpo de animal com mistura de traços humanos. Essas estranhas estátuas estão relacionadas com o que foi dito acima a respeito da temática mítica de ser engolido por um monstro marinho ou de ser batizado em um rito católico: são símbolos de ritos de passagem, que significam que todos os espíritos impuros devem ficar do lado de fora dos templos sagrados. Esse exemplo das gárgulas é somente um dentre muitos que Campbell (2007) estuda. É interessante destacar que o mesmo tema mitológico aparece na história de Jonas, em um rito do batismo cristão e no símbolo da gárgula que aparece em templos religiosos. Campbell (1994) fornece uma explicação clara de como antigos temas míticos ainda estão presentes em nosso cotidiano e que, de certo modo, passam despercebidos por grande parte dos sujeitos.

Outro jogo simbólico é encontrado por Campbell (2003) dentro do presépio natalino cristão. Nele encontramos, na maioria das vezes, a manjedoura com o menino Jesus, José, Maria, os três reis magos, além de animais. Entre esses animais, o autor propõe existir uma "mensagem oculta”, principalmente nas figuras do asno e do boi. Segundo o estudioso, esses dois animais eram simbólicos no Egito antigo e representavam o dualismo das forças opostas do bem e do mal: o asno era o animal do deus Seth, deus da inveja e da maldade, e o boi era símbolo do deus Osíris, deus da bondade e do renascimento. Como explica Campbell, esses dois símbolos antagônicos estão na manjedoura de Cristo para estabelecer uma reconciliação e para reconhecer a divindade de Cristo.

Com base na complexidade desses símbolos, o autor deseja mostrar como a simbologia de outras culturas se encontra embutida em outras tradições, e que, assim, passam a servir como ensinamentos doutrinários. No exemplo do presépio, os símbolos dos opostos, representados pelo boi e pelo asno, passam uma mensagem bíblica, uma "mensagem oculta" de cunho doutrinário sobre a existência do bem e do mal, entre outras interpretações.

O modo como interpreta os símbolos para explicar certas temáticas que ainda estão em voga (como o nascimento milagroso virginal, a jornada do herói, a crença no transcendente, entre outros mitos) faz das obras de Joseph Campbell uma importante referência antropológica e psicológica para o estudo dos mitos, crenças e religiões. É importante destacarmos que os estudos dos mitos entraram em declínio após a revolução cientificista, sobretudo após o Iluminismo, que os considerava como ilusões ou como uma coleção de contos baseados no absurdo e no erro. Campbell (1994) 
quebra esse paradigma ao trazer uma nova leitura desse mundo simbólico, redescobrindo temas míticos como fizeram Frazer (1982), Jung (2008), Freud (2006).

\section{Considerações finais}

Este artigo está longe de expressar a genialidade de Joseph Campbell, mas teve como objetivo apresentar aos leitores uma parcela dos estudos desse autor a partir da abordagem de uma de suas principais obras, $A$ imagem mítica, que congrega vários aspectos de seu pensamento, sua teoria e seus estudos.

Vimos a maneira como Campbell redescobriu a linguagem dos mitos, utilizando-se dos modelos comparativos com o intuito de estabelecer relações de semelhança entre os mais diversos símbolos e mitos das mais distintas culturas e civilizações. Apresentamos uma pequena exemplificação dessas comparações entre mitos ocidentais e orientais. Os estudos desse autor não se limitam aos temas apresentados, mas se expandem para os mais diversos campos das crenças, desde os antigos ritos totêmicos dos australianos até as mais atuais manifestações religiosas e filosóficas do mundo, o que demonstra uma incrível abrangência de temas, fruto de uma vida dedicada à exploração e à investigação.

Em uma de suas últimas obras intitulada $O$ poder do mito, Campbell faz uma espécie de resumo de seus estudos, com um enfoque para a vivência dos mitos nos dias de hoje. Ele conclui que a comparação entre mitos de povos distintos pode comprovar a chamada interconexão de experiência de vida, ou seja, o fato de haver semelhanças entre mitos e/ou símbolos de culturas distintas e em épocas diferentes pode apontar uma conexão vivencial que todos os seres humanos, independentemente de cultura, compartilham entre si. Essa visão também aparece nos estudos de Jung (2008), para quem os estudos em simbologia e mitologia comparadas demonstram que a humanidade está interligada espiritualmente e que, acima de qualquer diferença religiosa que possa existir, a alma humana possui as mesmas indagações sobre a existência, indagações essas que são coletivas e, portanto, iguais em qualquer parte do mundo.

O tema da coletividade humana também foi abordado pelo físico Capra (2003) com o seu postulado do novo paradigma científico. Embora os estudos de Ca- pra (2003) não estejam diretamente relacionados com o campo de estudo de Campbell (1994), o novo paradigma científico revela que, embora a civilização contemporânea esteja no auge dos avanços tecnológicos e científicos, o homem não deixou de possuir espiritualidade e de vivenciar o senso do religioso, o que vem ao encontro dos estudos de Jung (2008) e de Campbell (1994), que versam exatamente sobre esse ponto.

O estudo em mitologia comparada de Campbell (1994), a teoria do inconsciente coletivo de Jung (2008) e a proposta do novo paradigma científico de Capra (2003) levam-nos a crer que, de fato, existe uma espécie de interconexão dos sistemas de vida, ou melhor dizendo, uma subjetividade questionadora existencial coletiva, que clama por experiências e respostas que forneçam ao homem motivos para justificar sua vivência e para dar sentido às suas experiências. Esse é o papel fundamental dos mitos e dos símbolos.

\section{Referências}

ALVARENGA, M. Z. de et al. Mitologia simbólica: estruturas da psique e regências míticas. São Paulo: Casa do Psicólogo, 2010.

CAMPBELL, J. As máscaras de Deus: mitologia criativa. São Paulo: Palas Athena, 2010.

CAMPBELL, J. O poder do mito. São Paulo: Palas Athena, 2009.

CAMPBELL, J. As máscaras de Deus: mitologia ocidental. São Paulo: Palas Athena, 2008.

CAMPBELL, J. As máscaras de Deus: mitologia oriental. São Paulo: Palas Athena, 2008.

CAMPBELl, J. O herói de mil faces. São Paulo: Pensamento, 2007.

CAMPBELL, J. Tu és isso. São Paulo: Madras, 2003.

CAMPBELL, J. A imagem mítica. Campinas: Papirus, 1994.

CAPRA, F.; RAST, D. S.; MATUS, T. Pertencendo ao Universo: explorações nas fronteiras da ciência e da espiritualidade. São Paulo: Cultrix. 2003.

FRAZER, James. O ramo dourado. São Paulo: Círculo do Livro, 1982. 
FREUD, S. Obras psicológicas completas de Sigmund Freud. Rio de Janeiro: Imago, 2006.

JUNG, C. G. O homem e seus símbolos. Rio de Janeiro: Nova Fronteira, 2008.

JUNG, C. G. Os arquétipos e o inconsciente coletivo. Petrópolis: Vozes, 2008.
JUNG, C. G. Psicologia e religião oriental e ocidental. Petrópolis: Vozes, 1983.

MALLON, B. Os símbolos místicos. São Paulo: Larousse, 2009.

SANTOS, M. F. Tratado de simbólica. São Paulo: Logos, 1959. 


\section{Para publicar na revista}

Universitas Humanas,

acesse $o$ endereço eletrônico www.publicacoesacademicas.uniceub.br. Observe as normas de publicação, para facilitar e agilizar o trabalho de edição. 